JOURNAL OF APPLIED SMART ELECTRICAL
NETWORK AND SYSTEMS (JASENS)

\title{
Fuzzy Logic Controller sebagai Penentu Gerak Mobile Robot Pembasmi Hama
}

\author{
Muhammad Ridho Kenawas ${ }^{1}$, Pola Risma ${ }^{2}$, Tresna Dewi ${ }^{3}$, Selamet Muslimin ${ }^{4}$, and Yurni Oktarina ${ }^{5}$ \\ 1,2,3,4,5 Jurusan Teknik Elektro, Politeknik Negeri Sriwijaya \\ 1ridhk06@gmail.com,22polarisma@polsri.ac.id, ${ }^{3}$ tresna_dewi@polsri.co.id*, \\ ${ }^{4}$ selamet_muslimin@polsri.ac.id, ${ }^{5}$ yurni_oktarina@@polsri.ac.id
}

\begin{abstract}
A mobile robot is one of the solutions to overcome crop failure caused by chili pests. The mobile robot discussed in this paper is used to spray pesticide liquid into chili plant stems to prevent pests attack on the plants. This paper discusses the design of pesticide spraying robot motion with the application of Fuzzy Logic Controller. This robot employment is expected to reduce farmers' workload and to help to produce a good harvest. Robot motions are divided into two conditions, which can be controlled by remote control as a controller (manual) and by means of a sensor (automatic). Mobile robot movements have a significant impact on navigation and the design of the driving system. Robot speed is controller by adjusting Pulse Width Modulation of DC motors attached to the robots' wheel, which set to be 90 for slow and 220 for high speed. The Fuzzy Logic Controller in this mobile robot functions as an autonomous decision-making driver to detect obstacles in front of the mobile robot and the targeted stems.
\end{abstract}

Keywords : Mobile robot pest control, Remote control, Pulse width modulation, Fuzzy logic.

\begin{abstract}
Abstrak
Mobile robot merupakan solusi untuk mengatasi kerugian gagal panen yang disebabkan hama tanaman cabai. Mobile robot pada makalah digunakan untuk menyemprotkan cairan pestisida ke batang tanaman cabai untuk mencegah tanaman cabai tersebut terserang hama. Makalah ini membahas desain pergerakan robot penyemprot pestisida dengan aplikasi metode logika fuzzy. Penggunaan robot ini dapat mengurangi beban tenaga para petani dan membantu untuk mendapat hasil panen cabai yang baik. Pergerakan mobile robot dapat dibedakan menjadi dua kondisi yaitu dapat digerakan dengan remote control sebagai pengontrol (manual) dan menggunakan sensor (otomatis). Pergerakan mobile robot sangat berpengaruh pada navigasi dan desain sistem penggeraknya. Mobile robot ini digerakkan dengan putaran motor DC sebagai penggerak utamanya. Kecepatan putaran motor DC ini menggunakan pulse width modulation (PWM) dengan nilai yang diatur sebesar $90=$ slow dan $220=$ high. Metode logika fuzzy digunakan pada mobile robot difungsikan sebagai penggerak otonom pengambil keputusan secara cerdas, dalam mendeteksi halangan yang berada di depan mobile robot dan target yang sedang dituju.
\end{abstract}

Kata kunci : Mobile robot pembasmi hama, Remote control, Pulse width modulation, Logika fuzzy.

Diterima Redaksi : 07-06-2020 | Selesai Revisi : 11-06-2020 | Diterbitkan Online : 30-06-2020

\section{Pendahuluan}

Pada dunia industri, perkembangan teknologi robotik industri pertanian tanaman cabai. Usaha tanaman cabai memiliki banyak jenis robot yang digunakan, salah (Capsicum Annum L) merupakan komoditas jenis sayur satunya adalah mobile robot. Jenis robot ini merupakan yang populer dan menjanjikan keuntungan menarik jenis yang paling populer di dalam penelitian robotik. terkhusus di Indonesia karena permintaan cabai yang Mobile robot yang diartikan pergerakan atau gerak, tinggi. Untuk memulai usaha ini diperlukan modal yang diidientikan dengan ciri roda yang dapat berpindah besar dan keterampilan yang cukup. Namun, pada otomatis dari satu tempat ke tempat yang lain dengan kenyataannya usaha ini tidak sedikit para petani cabai bantuan navigasi, sehingga diharapkan mampu yang mengalami kerugian gagal panen, hal itu menggantikan pekerjaan manusia [1-7].
Jenis pekerjaan yang mampu digantikan oleh mobile robot di bidang industri salah satu contohnya adalah disebabkan oleh beberapa faktor, seperti faktor cuaca dan serangan hama tanaman [8-10]. 
Mobile robot digerakkan dengan motor DC yang sensor kamera, raspberry pi, mikrokontroler 328, menggunakan pulse width modulation (PWM) sebagai driver motor L298N, mini pump DC, dan motor DC. pengatur kecepatan putarannya. PWM ini merupakan Dimensi dari tingkat base ini dibuat sama dengan salah satu teknik modulasi yang mengubah lebar pulsa ukuran robot sebenarnya yaitu $37 \mathrm{~cm} \mathrm{x} 30 \mathrm{~cm}$ dengan dengan nilai frekuensi dan amplitudo yang tetap. Nilai menggunakan bahan akrilik. Pada bagian depan base output dari pulse width modulation (PWM) berupa mobile robot ini memilik 3 sensor ultrasonik dengan besar pulsa high dan low, dimana kita dapat mengontrol posisi kanan, kiri, dan tengah, dimana untuk posisi durasi pulsa high dan low tersebut sesuai yang kita kanan dan kiri membentuk sudut masing-masing inginkan dalam penelitian ini. Kendali gerak mobile sebesar $45^{\circ}$. Pada bagian belakang mobile robot ini robot ini dapat diatur dengan menggunakan kecerdasan dipasangkan baterai sebagai power utama penggerak buatan seperti fuzzy logic [11-17], neural network [18- mobile robot dengan tegangan sebesar $2200 \mathrm{mAh}$. 24], dan genetic algorithm [25].

Mobile robot merupakan solusi untuk mengatasi pada tanaman.

kerugian gagal panen yang disebabkan hama tanaman cabai, mobile robot digunakan untuk menyemprotkan cairan pestisida ke batang tanaman cabai. Penelitian ini menggunakan metode logika fuzzy yang dapat mengatur efektifitas keluaran data sensor sebagai pengatur gerak kecepatan mobile robot, penghindar halangan, dan mendeteksi objek yang akan dituju di depannya. Tujuan diadakannya penelitian ini untuk dapat mencegah tanaman cabai terserang hama, sehingga dapat mengurangi beban tenaga para petani dan menjaga para petani mendapatkan hasil panen cabai yang baik.

\section{Metode Penelitian}

Pada Gambar 1 menunjukkan diagram kerja pengembangan mobile robot. Metode fuzzy logic pada penelitian ini digunakan untuk mengatur kecepatan motor DC dengan range kecepatan yang sudah ditentukan dalam rules fuzzy logic dan mendeteksi jarak halangan dengan menggunakan data output sensor agar tidak terjadi tabrakan dan mencapai objek target yang ingin dituju.

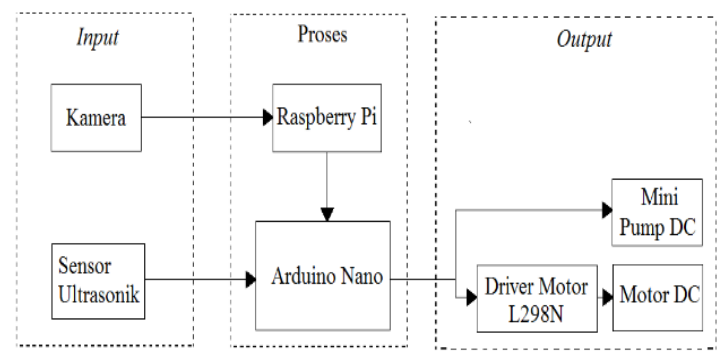

Gambar 1. Diagram Skematik Cara Kerja Alat Penelitian

\subsection{Design Mekanik}

Pada Gambar 1,2, dan 3 menunjukkan rancangan dari mobile robot pembasmi hama. Mobile robot ini memiliki detail ukuran sebagai berikut, panjang robot $37 \mathrm{~cm}$, tinggi robot $22 \mathrm{~cm}$, lebar robot $30 \mathrm{~cm}$, dan berat dimana $x i$ dan $y i$ merupakan sumbu $\mathrm{X}$ dan sumbu $\mathrm{Y}$ robot $1 \mathrm{~kg}$. Pada bagian base (tingkat utama) mobile dan $\emptyset i$ adalah orientasi mobile robot terhadap sumbu $Z$. robot ini telah di rancang dan diatur sebagai tempat Kecepatan robot adalah:

komponen-komponen utama mobile robot ini, seperti

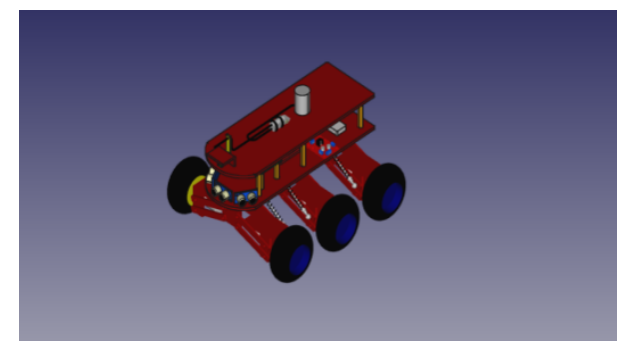

Gambar 2. Rancangan Mobile Robot Tampak Samping

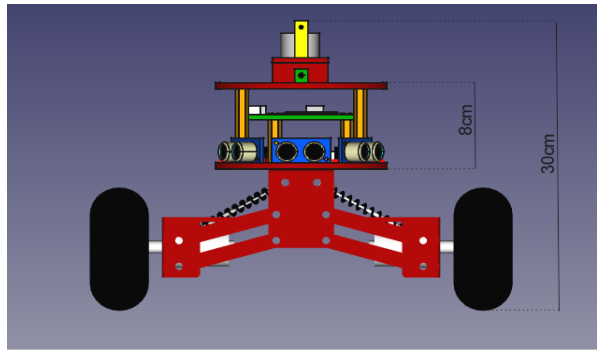

Gambar 3. Rancangan Mobile Robot Tampak Depan

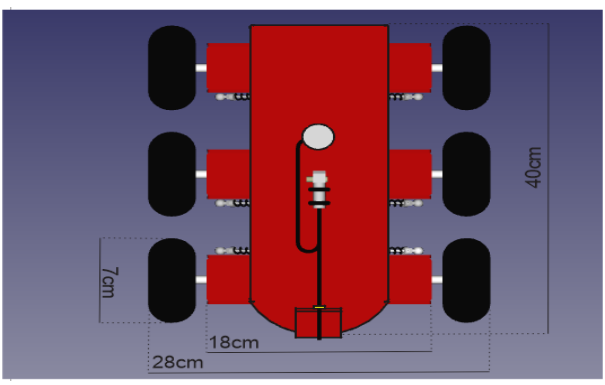

Gambar 4. Rancangan Mobile Robot Tampak Atas

Posisi mobile robot pada Gambar 2 dan 3 dirumuskan dengan:

$q i=[x i, y i, \emptyset i]^{T}$

(1)

Journal of Applied Smart Electrical Network and Systems (JASENS) 


$$
v=\left[v_{m 1}, v_{m 2}\right]^{T}
$$

(2)

dimana $v_{m 1}$ dan $v_{m 2}$ merupakan kecepatan motor kiri dan kanan.

Kontrol input yang diterapkan pada robot adalah:

$$
\mu=\frac{R}{2}\left(\dot{\theta}_{r}+\dot{\theta}_{l}\right)
$$

dimana $\dot{\theta}_{r}$ dan $\dot{\theta}_{l}$ merupakan orientasi roda kanan dan kiri. Kecepatan sudut diberikan oleh:

$$
\omega=\frac{R}{2 L}\left(\dot{\theta}_{r}-\dot{\theta}_{l}\right)
$$

dimana $\dot{\theta}_{r}$ dan $\dot{\theta}_{l}$ adalah roda kanan dan kiri kecepatan sudut masing-masing. Selama pergerakan mobile robot, sensor mendeteksi rintangan dan objek yang ingin dituju agar memberikan jarak minimum yang pasti untuk mempertimbangkan input ke pengontrol untuk mendapatkan kemudi mobile robot dan berpengaruh dengan kecepatan mobile robot $\left(v_{m 1}\right.$ dan $\left.v_{m 2}\right)$. Dalam penelitian ini, mobile robot diasumsikan hanya bergerak maju menghindari rintangan yang ada di depannya dan menuju target tanaman yang disemprot pestisida tanpa slipping dan skidding.

\subsection{Rancangan Elektrikal}

Pada Gambar 4 menunjukkan rancangan elektrik dari mobile robot pembasmi hama. Rancangan terdiri atas 3 buah sensor ultrasonik HC-SR04, 2 buah mikrokontroler Atmega 328, 1 buah raspberry pi dan modul kameranya, 3 buah driver motor L298 yang dipasang pararel, dan 7 buah motor DC (1 untuk mini рuтp). Adapun fungsi dari masing-masing komponen yaitu, sensor ultrasonik sebagai pendeteksi jarak antara halangan dan objek yang akan dituju di depan mobile robot, mikrokontroler Atmega 328 sebagai otak yang memproses perintah gerak dan cara kerja robot, raspberry pi sebagai alat yang memproses data yang ditangkap oleh modul kameranya dan ditransfer ke mikrokontroler Atmega 328 sebagai perintah, driver motor L298 sebagai pengatur kemudi mobile robot menentukan putaran aktuator kapan mobile robot harus berbelok, dan motor DC sebagai penggerak utama mobile robot.

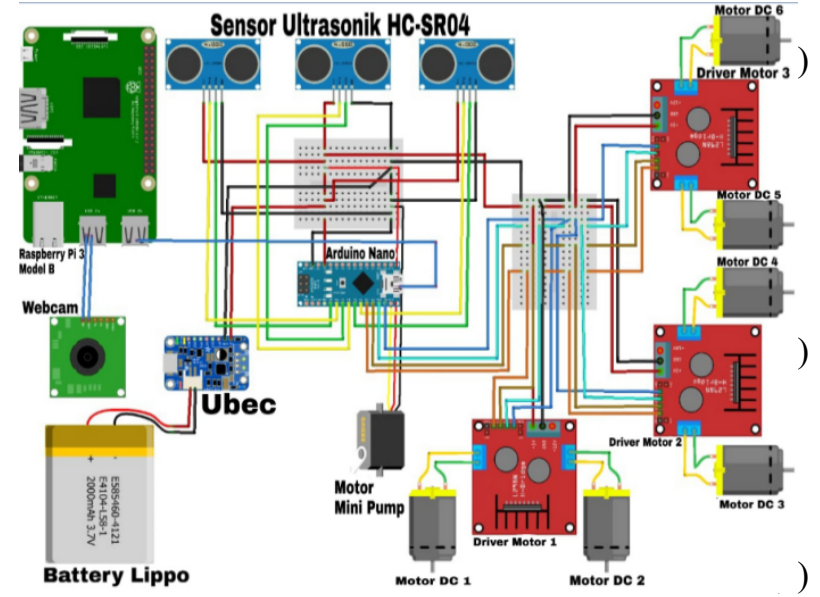

Gambar 5. Rancangan Elektrikal

\section{Hasil dan Pembahasan}

\subsection{Rancangan Kontrol Logika Fuzzy}

Pada Tabel 1, Gambar 6 dan 7 menunjukkan rules, input dan output logika fuzzy yang digunakan pada penelitian ini digunakan untuk sistem pengaturan gerak robot penghindar halangan cerdas dan menggunakan metode mamdani dalam proses simulasinya . Logika fuzzy dipilih karena memiliki beberapa kelebihan, seperti kontrol sederhana, biaya rendah, dan dapat digambarkan sebagai penghitung kata daripada angka atau mengendalikan dengan kalimat persamaan. Dalam hal ini logika fuzzy menunjukkan sejauh mana suatu nilai dapat dikatakan benar atau salah. Penelitian ini menggunakan bentuk triangular kurva sebagai pembentukan variabel fungsi dari 4 input pada membership fuzzy logic yang dimana menggunakan 3 ultasonik sebagai sensor jarak dan kamera sebagai sensor citra dan 2 output motor DC dari tiga roda masing-masing roda kanan dan kiri. Variabel dan himpunan ini akan diaplikasikan pada mobile robot

\begin{tabular}{|c|c|c|c|c|c|c|c|}
\hline \multicolumn{4}{|c|}{ Input } & \multicolumn{3}{|c|}{ Output } & \multirow[b]{2}{*}{$\begin{array}{l}\text { Information } \\
\text { Mobile Robot }\end{array}$} \\
\hline $\begin{array}{c}\text { Ultrasonic } 1 \\
\text { (Left) }\end{array}$ & $\begin{array}{c}\text { Ultrasonic 2 } \\
\text { (Middle) }\end{array}$ & $\begin{array}{c}\text { Ultrasonic } 3 \\
\text { (Right) }\end{array}$ & Camera & Left Wheel & Right Motor & Mini Pump & \\
\hline Near & Near & Near & Detect & Stop & Stop & On & Forward \\
\hline Near & Near & Medium & Error Detect & Stop & Stop & Off & Turn Right \\
\hline Near & Near & Far & Detect & Slow & Slow & On & Turn Right \\
\hline Near & Medium & Near & Error Detect & Slow & Slow & Off & Forward \\
\hline Near & Medium & Medium & Detect & Normal & Normal & On & Turn Right \\
\hline Near & Medium & far & Error Detect & Normal & Normal & Off & Turn Right \\
\hline Near & Far & Near & Detect & Normal & Normal & On & Forward \\
\hline Near & Far & Medium & Error Detect & Normal & Normal & Off & Forward \\
\hline
\end{tabular}
[8][9].

Tabel 1. Rule Fuzzy Logic Mobile Robot Pembasmi Hama 


\begin{tabular}{|c|c|c|c|c|c|c|c|}
\hline var & Far & Far & Detect & Normal & Normal & on & Forward \\
\hline Near & Near & Near & Error Detect & Stop & Stop & off & Turn Left \\
\hline Medium & Near & Medium & Detect & Stop & Stop & On & Turn Left \\
\hline Medium & Near & Far & Error Detect & Slow & Slow & off & Turn Right \\
\hline Medium & Medium & Near & Detect & Slow & Slow & on & Turn Left \\
\hline Medium & Medium & Medium & Error Detect & Slow & Slow & off & Forward \\
\hline Medium & Medium & Far & Detect & Slow & Slow & On & Forward \\
\hline Medium & Far & Near & Error Detect & Normal & Normal & off & Forward \\
\hline Medium & Far & Medium & Detect & Normal & Normal & on & Turn Left \\
\hline Medium & Far & Far & Error Detect & Normal & Normal & off & Forward \\
\hline Far & Near & Near & Detect & Stop & Stop & on & Forward \\
\hline Far & Near & Medium & Error Detect & Stop & Stop & off & Forward \\
\hline Far & Near & Far & Detect & Stop & Stop & On & Turn Left \\
\hline Far & Medium & Near & Error Detect & Slow & Slow & off & Turn Left \\
\hline Far & Medium & Medium & Detect & Slow & Slow & On & Turn Left \\
\hline Far & Medium & Far & Error Detect & Slow & Slow & off & Turn Left \\
\hline Far & Far & Near & Detect & Normal & Normal & on & Forward \\
\hline Far & Far & Medium & Error Detect & Fast & Fast & off & Forward \\
\hline Far & Far & Far & Detect & Fast & Fast & on & Forward \\
\hline
\end{tabular}

Hasil himpunan fuzzy memiliki sistem proses, sistem prosesnya antara lain fuzzification, yang merupakan aturan yang digunakan sistem fuzzy dimana mengubah nilai input atau masukan yang nilai kebenarannya bersifat pasti (crisp input) ke dalam fuzzy, yang berupa nilai linguistik yang digunakan berupa near, medium, far, dan detect, error detect, berdasarkan fungsi dari keanggotaan tertentu [11]. Berikutnya ada inference, inference merupakan penalaran menggunakan fuzzy input dan fuzzy rules yang telah ditentukan sebelumnya untuk menghasilkan fuzzy output. Pada penelitian ini inference yang digunakan yaitu, IF proximity sensor AND camera sensor THEN motor DC take.
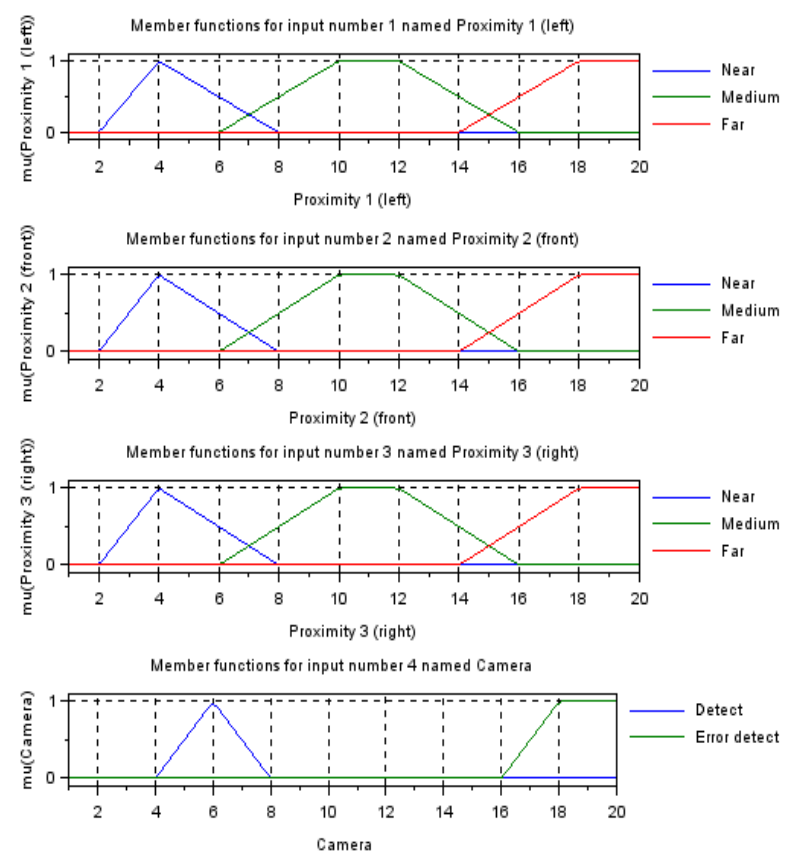

Gambar 6. Membership function dari Input yang disimulasikan dengan Scilab
Hasil himpunan fuzzy bahwa inputan 2 variabel, dimana inputan pertama, 3 sensor jarak yang mana inputnya terdiri dari 3 tahapan ukuran jarak sensor, dimana Near (2cm-8cm), Medium (6cm-16cm), dan Far (14cm$20 \mathrm{~cm})$. Sementara input kedua, 1 kamera sebagai sensor citra yang mana inputnya terdiri dari 2 tahapan deteksi kamera, dimana Detect $(4 \mathrm{~cm}-8 \mathrm{~cm})$ dan Error detect $(16 \mathrm{~cm}-20 \mathrm{~cm})$.
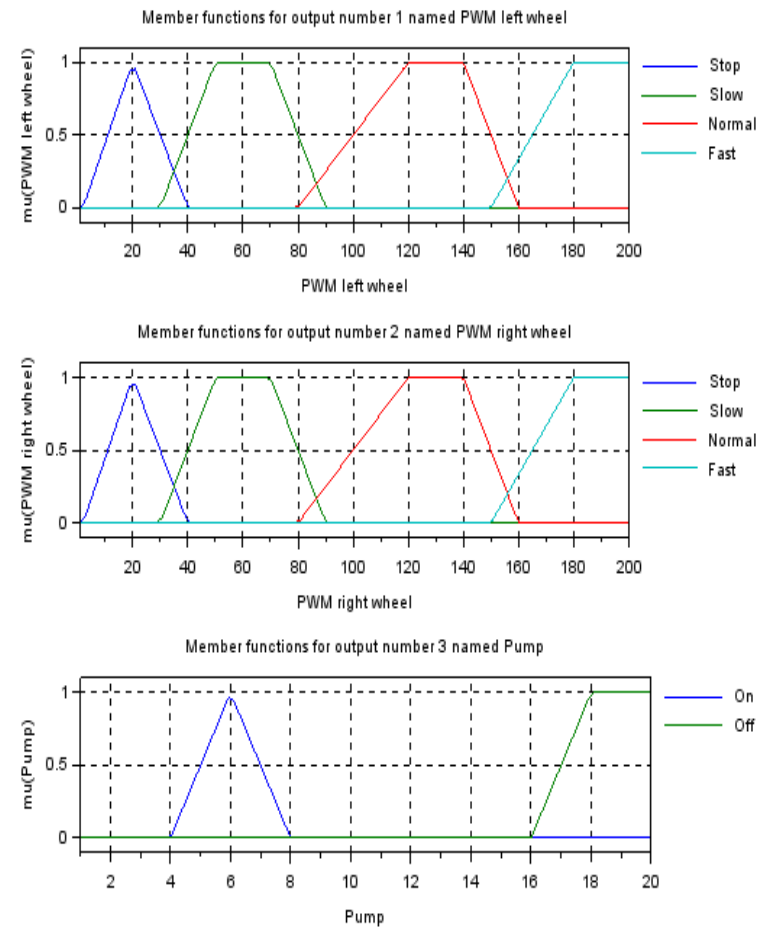

Gambar 7. Membership function dari Output yang disimulasikan dengan Scilab

Hasil himpunan fuzzy output 2 variable, dimana output pertama, 2 motor DC untuk roda kanan dan kiri (PWM) yang masing-masing 3 roda, terdiri dari 4 tahapan kecepatan laju motor DC, dimana Stop (2rpm-40rpm), Slow (30rpm-90rpm), Normal (80rpm-160rpm), dan Fast (150rpm-220rpm). Sementara output kedua, 1 motor DC sebagai mini pump yang mana outputnya terdiri atas 2 tahapan kerja mini pump DC, dimana On $(4 \mathrm{~cm}-8 \mathrm{~cm})$ dan Off $(16 \mathrm{~cm}-20 \mathrm{~cm})$.

Output ini terhubung ke perputaran motor DC dengan PWM yang telah diatur pada range untuk Slow 30rpm220rpm untuk Fast dan mini pump yang diatur on dan off dengan logika High (1 = mini pump aktif) dan Low (logika $0=$ mini pump non-aktif).

Logika fuzzy yang diterapkan pada penelitian ini dirancang untuk memberikan feedback dari sensor terhadap kecepatan perputaran motor untuk gerak mobile robot dan output mini pump untuk menyemprotkan cairan pestisida sebagai pembasmi hama tanaman. 


\subsection{Rancangan Simulasi Mobotsim Mobile Robot}

Pada Gambar 8 dan 9 menunjukan bahwa pada penelitian ini, metode fuzzy logic pada mobile robot pembasmi hama yang diimplementasikan terbukti dengan melakukan simulasi percobaan menggunakan software mobotsim. Mobotsim merupakan software desain 2D yang dikonfigurasikan menjadi simulator mobile robot yang merancang robot dengan kecerdasan buatan seperti fuzzy logic dan neural network. Mobotsim ini difungsikan untuk menunjukkan lintasan robot selama robot bergerak dari awal sampai akhir menuju target-target yang telah ditentukan [12].

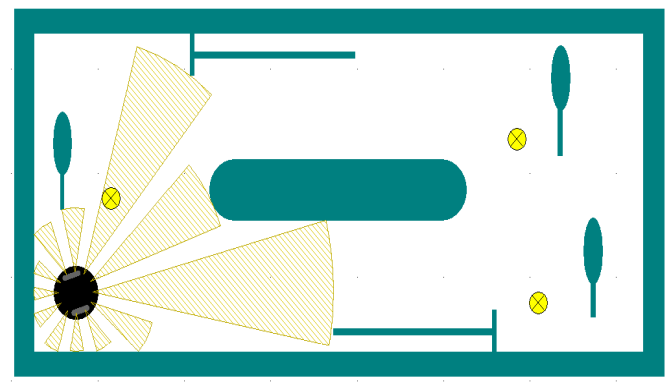

Gambar 8. Posisi Awal Mobile Robot

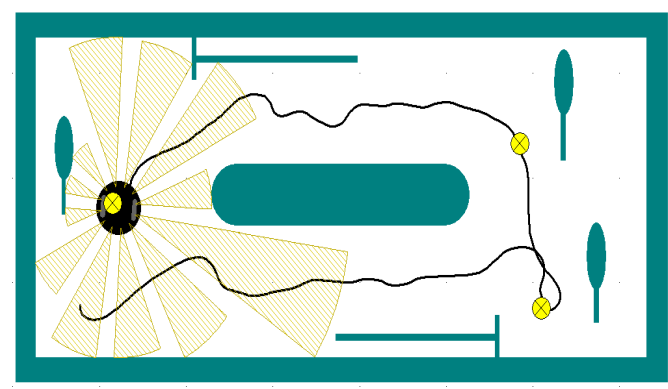

Gambar 9. Posisi Akhir Mobile Robot Mencapai Target

\section{Kesimpulan}

Dari penelitian yang telah dilakukan ini, mobile robot ini dibuat bertujuan untuk membantu para petani mengatasi serangan hama, maka dengan proses kontrol gerak mobile robot dengan menggunakan metode logika fuzzy. Dengan menggunakan metode logika fuzzy untuk kendali robot pada lintasan tidak beraturan dapat menghasilkan pengambilan keputusan jalur tanpa hambatan (halangan) tanpa mengenainya dan sampai kepada objek (tanaman) yang dituju untuk menyemprotkan pestisida dan laju mobile robot menyesuaikan dengan kecepatan putaran motor DC dengan menggunakan pulse width modulation (PWM).

\section{Daftar Rujukan}

[1] Hendrix R., Owan P., Garbini J., and Devasia S., 2019. Context-Specific Separable Gesture Selection for Control of a Robotic Manufacturing Assistant. IFAC PapersOnline, 51(34), pp. 89-96.

[2] Dewi T., Nurmaini S., Risma P., Oktarina Y., and Roriz M., 2019, Inverse Kinematic Analysis of 4 DOF Pick and Place
Arm Robot Manipulator using Fuzzy Logic Controller, IJECE, 10(2), pp. 1376-1386. doi:10.11591/ijece.v10i2.pp1376-1386.

3] Uchiyama N., Dewi T., and Sano S., 2014, Collision Avoidance Control for a Human-Operated Four Wheeled Mobile Robot, Proceedings of the Institution of Mechanical Engineers, Part C: Journal of Mechanical Engineering Science, 228(13), pp. 22782284. https://doi.org/10.1177/0954406213518523.

[4] Dewi T., Amperawan, Risma P., Oktarina Y., and Yudha D. A., 2020, Finger Cue for Mobile Robot Motion Control, Computer Engineering and Application Journal, 9(1), pp. 39-48. doi: 10.18495/COMENGAPP.V9I1.319.

[5] Uchiyama N., Dewi T., Sano S., and Takahashi H., 2014 Swarm Robot Control for Human Services and Moving Rehabilitation by Sensor Fusion, Journal of Robotics, 2014(278659), 11 pages. https://doi.org/10.1155/2014/278659.

[6] Oktarina Y., Dewi T., and Risma T., 2020, The Concept of Automatic Transport System Utilizing Weight Sensor, Computer Engineering and Application Journal, 9(2), pp. 155163. doi:10.18495/COMENGAPP.V0I0.339

[7] Dewi T., Risma P., Taqwa A., Rusdianasari, and Renaldi H., 2020, Experimental analysis on solar powered mobile robot as the prototype for environmentally friendly automated transportation, Proc. iCAST on Engineering Science, 24-25 Oct 2019, Bali: Indonesia, doi:10.1088/1742-6596/1450/1/012034.

[8] Dewi T., Risma P., Oktarina Y., and Muslimin S., 2018, Visual Servoing Design and Control for Agriculture Robot; a Review, pp. 57-62, Proc. 2019 ICECOS, 2-4 Oct. 2018, Pangkal Pinang: Indonesia. doi: 10.1109/ICECOS.2018.8605209.

[9] Dewi T., Risma P., and Oktarina Y., 2020, Fruit Sorting Robot based on Color and Size for an Agricultural Product Packaging System, Bulletin of Electrical Engineering, and Informatics (BEEI), 9(4), pp. 1438-1445. doi: 10.11591/eei.v9i4.2353.

[10] Oktarina Y., Dewi T., Risma P., and Nawawi M., 2020, Tomato Harvesting Arm Robot Manipulator; a Pilot Project, Journal of Physics: Conference Series, 1500, p 012003, Proc. $3^{\text {rd }}$ FIRST, Palembang: Indonesia.

[11] Al Yahmedi A.S., and Fatmi M.A., 2016. Fuzzy Logic Based Navigation of Mobile Robots," Intech, 6, pp. 111-133.

[12] Nurmaini S., Tutuko B., Dewi K., Yuliza V., and Dewi T., 2017, Improving Posture Accuracy of Non-holonomic Mobile Robot system with Variable Universe of Discourse, TELKOMNIKA, 15(3). Pp. 1265-1279. doi: 10.12928/TELKOMNIKA.v15i3.6078.

[13] Dewi T., Wijanarko Y., Risma P., and Oktarina Y., 2018, Fuzzy Logic Controller Design for Leader-Follower Robot Navigation, 5th Proc. EECSI, 5(1), pp. 298-303. 16-18 Oct 2018, Malang : Indonesia. doi:10.1109/EECSI.2018.8752696.

[14] Dewi T., Risma P., and Oktarina Y., 2018, Fuzzy Logic Simulation as a Teaching-learning Media for Artificial Intelligence Class, Journal of Automation Mobile Robotics and Intelligent Systems, 12(3), pp. 3-9.doi: 10.14313/JAMRIS_32018/13

[15] Dewi T., Oktarina Y., Risma P., and Kartini S., 2019, Desain Robot Pengikut Manusia Sederhana dengan Fuzzy Logic Controller, Proc. Annual Research Seminar (ARS), 5(1), pp. 1216, 16 Nov 2019, Palembang: Indonesia.

16] Oktarina Y., Septiarini F., Dewi T., Risma P., and Nawawi M., 2019, Fuzzy-PID Controller Design of 4 DOF Industrial Arm Robot Manipulator, Computer Engineering and Application $\begin{array}{llll}\text { Journal, } & 8(2), & \text { pp. } & 123-136 .\end{array}$ 10.18495/COMENGAPP.V8I2.300.

17] Dewi T., Sitompul C., Risma P., Oktarina Y., Jelista R., Mulyati M., 2019, Simulation Analysis of Formation Control Design of Leader-Follower Robot Using Fuzzy Logic Controller, Proc 2019 ICECOS, 2-3 Oct. 2019, Batam Island: Indonesia. doi:10.1109/ICECOS47637.2019.8984433.

[18] Farooq U., Amar M., Asad M.U., Hanif A., and Saleh S.O. 2014. Design and Implementation of Neural Network of Based Controller for Mobile Robot Navigation in Unknown Environment. International Journal of Computer and Electrical Engineering, 6(2), pp. 83-89. doi:10.7763/IJCEE.2014.V6.799

19] Yudha H. M., Dewi T., Hasana N., Risma P., Oktarina, Y. Kartini S., 2019, Performance Comparison of Fuzzy Logic and Neural Network Design for Mobile Robot Navigation, Proc. 2019 ICECOS, 2-3 Oct. 2019, Batam Island: Indonesia. doi:10.1109/ICECOS47637.2019.8984577 
[20] Larasati N., Dewi T., and Oktarina Y., 2017. Object Following Design for a Mobile Robot using Neural Network. Computer Engineering and Application Journal, 6(1), pp. 5-14. doi:10.18495/COMENGAPP.V6I1.189.

[21] Dewi T., Risma P., Oktarina Y., and Roseno M.T., 2017. Neural Network Design for a Mobile Robot Navigation a Case Study. 4th Proc. EECSI. 23-24 Sep. 2017. Yogyakarta: Indonesia. doi:10.1109/EECSI.2017.8239168.

[22] Dewi T., Risma P., Oktarina Y., and Nawawi M., 2017. Neural Network Simulation for Obstacle Avoidance and Wall Follower Robot as a Helping Tool for Teaching-Learning Process in Classroom. 1st Proc. ICEAT, 29-30 November 2017, Mataram: Indonesia. doi:10.1088/1757-899X/403/1/012043

[23] Risma P., Dewi T., Oktarina Y., and Wijanarko Y., 2019 Neural Network Controller Application on a Visual based
Object Tracking and Following Robot. Computer Engineering and Application Journal, 8(1). doi: 10.18495/COMENGAPP.V8I1.280.

[24] Kuswad S., Natasya A., Tamara M.N., and Adji I., 2018. Optimasi Sistem Navigasi Robot Bencana Dengan Algoritma Bug Dan Jaringan Syaraf Tiruan. JTIIK, . 5(5), pp. 635-642.

[25] Savage J., Muoz S., Matamoros M., and Osorio R., 2013 Obstacle Avoidance Behaviors for Mobile Robots Using Genetic Algorithms and Recurrent Neural Networks. IFAC, 46(24), pp. 141-146. 